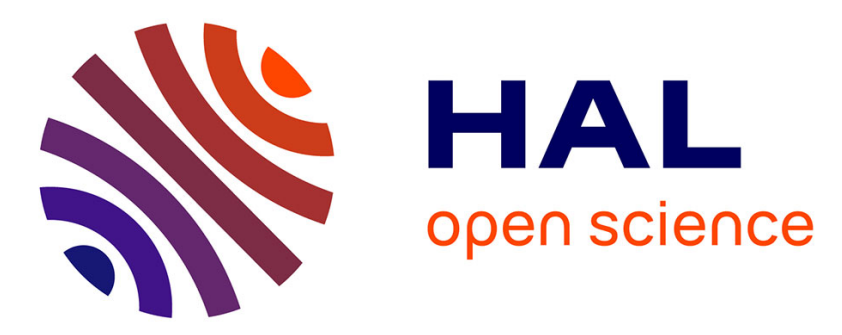

\title{
Reliability Assessment of Multistate Degraded Systems: An Application to Power Electronic Systems
}

\author{
Vahid Samavatian, Hossein Iman-Eini, Yvan Avenas
}

\section{To cite this version:}

Vahid Samavatian, Hossein Iman-Eini, Yvan Avenas. Reliability Assessment of Multistate Degraded Systems: An Application to Power Electronic Systems. IEEE Transactions on Power Electronics, 2020, 35 (4), pp.4024-4032. 10.1109/TPEL.2019.2933063 . hal-03260255

\section{HAL Id: hal-03260255 \\ https://hal.science/hal-03260255}

Submitted on 14 Oct 2021

HAL is a multi-disciplinary open access archive for the deposit and dissemination of scientific research documents, whether they are published or not. The documents may come from teaching and research institutions in France or abroad, or from public or private research centers.
L'archive ouverte pluridisciplinaire HAL, est destinée au dépôt et à la diffusion de documents scientifiques de niveau recherche, publiés ou non, émanant des établissements d'enseignement et de recherche français ou étrangers, des laboratoires publics ou privés. 


\title{
Reliability Assessment of Multistate Degraded Systems: An Application to Power Electronic Systems
}

\author{
Vahid Samavatian, Hossein Iman-Eini, Senior Member, IEEE and Yvan Avenas
}

\begin{abstract}
This paper demonstrates the feasibility of using multistate degraded system analysis for obtaining much more accuracy in reliability evaluation. The proposed method is capable of estimating system-level reliability, while mission profile and physics of failure of the system's items are taken into account. In addition, the self and mutual degradation effects of items on the operation of the global system have been considered. Not only does the proposed framework can be employed in determining the reliability of the degraded systems in terms of multi-state functions, but also obtains the states of the systems by estimating the system state probabilities. As an application, a power electronic system containing three critical items has been studied. In this case study, two power semiconductors and a capacitor have been considered as three degradation processes and their aging effects on the useful lifetime estimation of the power electronic system has been discussed.
\end{abstract}

Index Terms - Lifetime estimation, Multistate degraded systems, Power electronic systems, Reliability.

\section{INTRODUCTION}

$\mathrm{C}$ ONVENTIONAL binary-state reliability model in which only two possible states, namely perfectly functioning and complete failure, are assumed for a system and its components are inadequate to present the multistate inherent of complicated engineered systems [1]-[3]. In many real engineered applications, particularly power electronic systems, there exist several intermediate states for characterizing health of the systems [4], [5]. Therefore, a multistate system model is able to manifest sophisticated degrading (aging) behaviors of the engineered system beyond binary-state model [6]-[9].

The deteriorating process of a component or a system may be accelerated owing to aging. Accordingly, static reliability assessment has not been able to estimate the reliability of a system [10]. A dynamic reliability assessment method for multistate system through the aggregation of multilevel inspection data is developed [11], [12]. In these studies, the state of a system is extracted owing to the imperfections of inspections. The inspection data are able to be simultaneously or asynchronously gathered across multiple levels of the system. Although, the reliability function of the system can be dynamically updated, this method is unable to address the cases in which an inspector is related to multiple components which is the case in engineered systems.

Stochastic processes [13], [14], extended decision diagrambased methods [15]-[17] and the universal generating functions

V. Samavatian is with the School of Electrical and Computer Engineering, College of Engineering, University of Tehran, Tehran, Iran and the Univ. Grenoble Alpes, CNRS, Grenoble INP (Institute of Engineering Univ. Grenoble Alpes), G2Elab, 38000 Grenoble, France (e-mail: vahidsamavatian@ut.ac.ir, vahid.samavatian@g2elab.grenoble-inp.fr).
(UGFs) [18], [19] have proposed some frameworks for dynamic reliability assessment in which the failure rate of items have been considered time-dependent. Although, the model is capable of considering degradation dependencies, its implementation for the higher number of components is complicated and time consuming. Furthermore, they are failing to consider the mission profile of the system.

Liu et al. [20] proposed a new reliability model for multistate systems with state transition dependency. They used copula functions to characterize the dependency among state transitions and to construct a multivariate distribution. Huge computational burden owing to the high-dimensional integration in the likelihood function and more unknown parameters is the main detriment of this approach.

In order to attain the reliability specifications and risk functions of multistate systems, an approach based on an inverse $\mathrm{L}_{\mathrm{z}}$ transform is proposed by Lisnianski et al. [21]. However, the dependency of system components is not taken into account. Song et al [22] proposed stochastic multi-valued models for evaluating the reliability of a multistate system with dependent multistate components. The major defect in this method is the difficulty of precise performance estimation of multistate components due to the challenges associated with the probability of the state's determination.

A multi-layered vector-valued continuous-time Markov chain was utilized to obtain a stochastic dependency [20] among multi-state components in [23], [24] and an aggregated Markov process was employed to mitigate the computational complexity resulting from system reliability evaluation. However, its inability to take into account the self-degradation of components and lack of consideration of mission profile and failure root causes are the detriments of this method.

Failure to consider mission profile of the system, inability to take into account the mutual and self-degradation effects (dependencies) on the performance of system, inability to use deterministic knowledge (i.e. physics of failure which is necessary for design for reliability in the engineering systems), inability to correlate components states to the system states that may simplify the extraction of data inspection and complexity of implementation are detriments of the aforementioned studies posing considerable challenges in reliability assessment of multistate degraded systems.

To bridge above gap, a novel physics of failure (PoF) based reliability assessment framework is proposed in this paper. This

H. Iman-Eini is with the School of Electrical and Computer Engineering, College of Engineering, University of Tehran, Tehran, Iran (e-mail: imaneini@ut.ac.ir).

Y. Avenas is with the Univ. Grenoble Alpes, CNRS, Grenoble INP (Institute of Engineering Univ. Grenoble Alpes), G2Elab, 38000 Grenoble, France (email: yvan.avenas@g2elab.grenoble-inp.fr). 
method converts a dependent system to a multistate independent system by discretizing the global system states to the specific state space. In each state of the global system, detached operating conditions are assumed. In the proposed method, the mission profile of the undertaken system has been considered as shown in Fig. 1. The translated mission profile has been applied to the Rainflow algorithm in order to sort the complex data to the understandable data. The sorted data is also applied to the lifetime model of an item. The output of the lifetime model is one or more failure indicators. The trends of failure indicators have been curve-fitted and finally applied to the main multistate degraded system reliability assessment. Based on the failure criterion of each item and its corresponded degradation levels, a state for the system will be defined. Accordingly, multistate system is defined based on the items' degradation states.

The remainder of this paper is as follows. Section II puts forward the newly proposed multistate degraded system reliability assessment. Section III deals with the proposed method's application to power electronic system and expressing experimental procedure. While results and discussion are presented in section IV, a conclusion is drawn in section $\mathrm{V}$.

\section{Multistate Degraded Systems}

Multistate degraded system analyzing flowchart is shown in Fig. 2. Based on the field experiences and analytic investigation, one can divide the components into two different categories, namely effective and ineffective. Effective items' degradation directly affect the system reliability by changing its state. However, it is not the case in the ineffective components. These items directly cause the system to the failure state provided that they reach to their failure criteria. Regarding this figure, degradation processes of system's components and their uncertainties are applied to the effective items in which their degradations affect the system state. For effective components, different functional states as well as their corresponding intervals are defined. Then system functional state space and the mapping function $\left(\mathrm{H}_{\mathrm{C}}\right.$ matrix) between components states and system states are defined. Finally, one can estimate system reliability by assessing non-failure system states' probabilities and reliability of ineffective as well.

\section{A. System Description}

A system can be constituted by several subsystems or items which are exposed to various failure processes. In a reliability point of view, some important issues have to be considered: 1) the degradation of every item does not follow a constant trend (constant failure rate) due to the wearing out manner which is also accelerated by aging, 2) the degradations of different items can affect the degradation process of the other items by changing the operational point of the considered system and 3) mission profile does play a central role on the wearing out behavior of the items. Accordingly, the degradation trends (process) of the items have to be considered based on the mission profile. In addition, by dividing different system degraded states (new operational points), the effect of mutual and self-degradations of the items in the system will be considered. The degradation process of effective items are

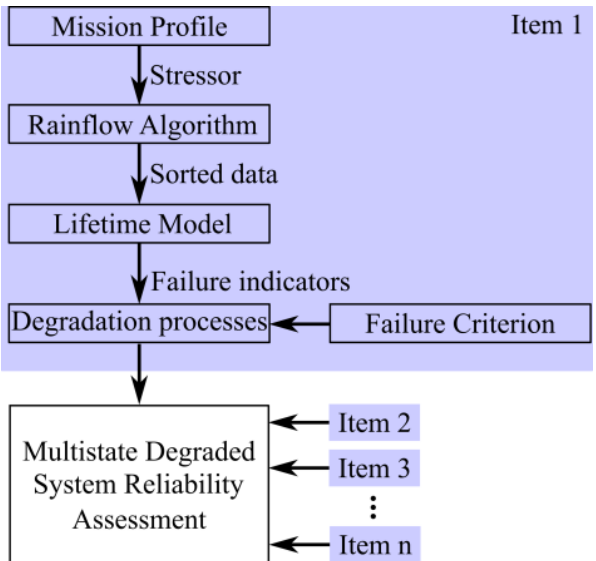

Fig. 1. Global flowchart of reliability assessment of an n-component system

considered as a function of time and denoted by $\mathrm{Y}_{\mathrm{i}}(\mathrm{t}), \mathrm{i}=1,2$, $\ldots, \mathrm{k}$. However, the degradation of ineffective items do not affect the system operating points (system state). Therefore, there is no need of considering degradation processes and only their complete failures $\left(D_{\ell}(t), j=1,2, \ldots, \ell\right)$ can affect system's failure. $\mathrm{k}$ and $\ell$ are the number of effective and ineffective items, respectively (also $\mathrm{k}+\ell=\mathrm{n}$, where $\mathrm{n}$ is the total number of items in the global systems).

Since every item is initially in its perfect states $\left(\mathrm{M}_{\mathrm{i}}\right)$, the global system is also being in its perfect state. By time passing (aging), the effective items may reach either another degraded state, namely $(\mathrm{M}-1)_{\mathrm{i}}$, or system failed state $(\mathrm{F})$. After degradation, the item can reach the other state, namely $(\mathrm{M}-2)_{\mathrm{i}}$ or failure state. A transition may be occurred from any system states to the failure state whenever an ineffective item fails owing to the random shock which is subjected to.

The degradation process may continue and passed all the aging stages till the last degradation state, i.e. $0_{\mathrm{k}}$ reaches. If the system reaches the last degradation state, there is an imperfection in the functionality of the system, and the system must be considered as a failure (state 0). Fig. 3 demonstrates the system block diagram of the multiple competing degradation processes including effective and ineffective items. In Fig. 3, the above part presents the degradation process of effective items (components) and the bottom part presents the degradation

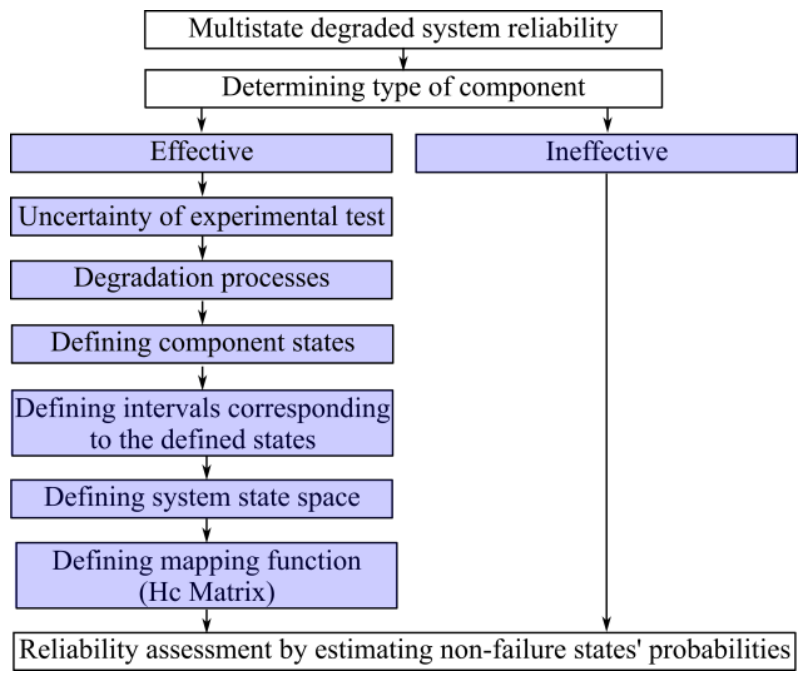

Fig. 2. Analysis procedure of multistate degraded system (see Fig. 1) 
process of ineffective items. While ineffective items may directly lead to the catastrophic failure owing to the mission profile they are exposed to, the degradation processes of the effective items may lead an item to transmit from healthier state to either the more degraded states or the catastrophic failure state. Although the system can continue working during the degraded states, it does not work in the perfect state. Thereby, some imperfect states have to be defined for the system as shown in Fig. 3.

\section{B. Method assumptions}

Some assumptions in formulating this newly proposed method have been defined as follows:

1. The system consists of $M+2$ states in which state 0 and state $\mathrm{F}$ are both complete failure states. State 0 represents that the degradation threshold has been exceeded and state $F$ demonstrates a complete (catastrophic) failure occurred by ineffective items or sudden defects in the effective items as shown in Fig. 3.

2. It is assumed that there is no repair and maintenance performing on the system (system is non-repairable).

3. It is assumed that degradation processes of effective items, i.e. $Y_{i}(t)$, are nonnegative, strictly non-decreasing functions at time $\mathrm{t}$ owing to irreversible accumulation of damages.

4. It is assumed that $Y_{i}(t), i=1,2, \ldots, k$ and $D_{j}(t), j=1,2, \ldots, \ell$ are statistically independent. It means that the degradation process of one item in its specific state does not have an effect on the others.

5. The system is in the perfect state at time $t=0$.

6. The system may fail either owing to the each effective degradation process, i.e. $Y_{i}(t)>G_{i}, i=1,2, \ldots, k$ or owing to each ineffective degradation process, e.g. $D_{j}(t ; \eta, \beta) \sim W_{j}(\eta, \beta)>B_{s j}, j=1$, $2, \ldots, \ell$. Where $G_{i}$ and $S_{j}$ are the critical values for effective degradation processes and threshold value in which the probability of failure process will reach a specified point $\left(S_{j}\right)$ for ineffective items, respectively.

7. The critical value $G_{i}$ depends upon the function of intermediate degradation states of the systems.

\section{Methodology}

As it was mentioned, the degradations of different effective items can affect the degradation processes of the other items by changing the operational point of the system. For example, by degradation of item 1 , some of its critical values will vary which can change the operating point of the system and lead to accelerated aging of the other items. This accelerated aging caused by the other items has been called mutual degradation effects. This operating point change can also accelerate item 1 degradation. This accelerated aging caused by the item itself has been called self-degradation effects.

\section{C.1 Formulating Effective Degradation Processes in Terms of Discrete State Space Sets}

$\mathrm{k}$ effective degradation processes have been considered here. For each of them, a finite number of different discrete states has been also taken into account. The state space is denoted by $\boldsymbol{\Omega}_{\mathrm{i}}=\left\{\mathrm{M}_{\mathrm{i}},(\mathrm{M}-1)_{\mathrm{i}}, \ldots, 1_{\mathrm{i}}, 0_{\mathrm{i}}\right\}, \mathrm{i}=1,2, \ldots, \mathrm{k}$ corresponding to the degradation process $i$ with $M_{i}+1$ states. $M_{i}, i=1,2, \ldots, k$ may or may not be the same and $\mathrm{M}_{\mathrm{i}}<\infty$.

Degradation processes are defined by the finite number of

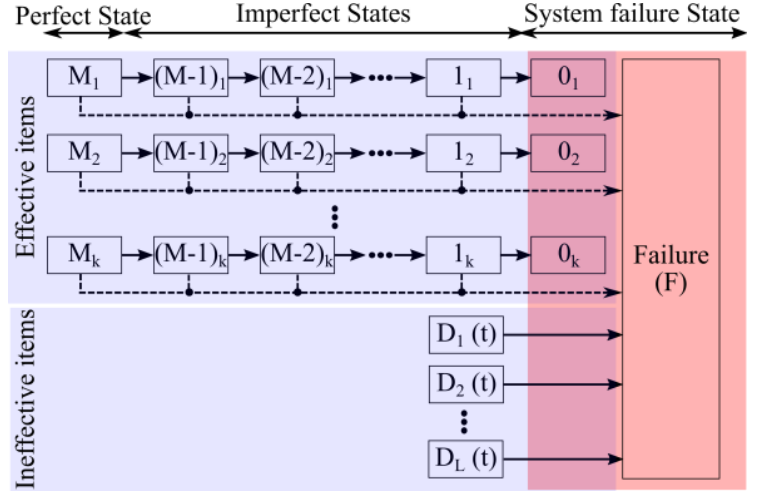

Fig. 3. Block diagram of the $n$-component system subjected to multiple failure processes.

states. As an example, $\mathrm{Y}_{\mathrm{i}}(\mathrm{t})$ falls into predefined intervals corresponding to the specified intermediate degradation states. Let define the intervals as follows: $\left[0, \mathrm{~W}_{\mathrm{Mi}}\right],\left(\mathrm{W}_{\mathrm{Mi}}, \mathrm{W}_{(\mathrm{M}-1) \mathrm{i}}\right], \ldots$, $\left(\mathrm{W}_{2 \mathrm{i}}, \mathrm{W}_{1 \mathrm{i}}\right]$ where $\mathrm{W}_{\mathrm{Mi}}>\mathrm{W}_{(\mathrm{M}-1) \mathrm{i}}>\mathrm{W}_{(\mathrm{M}-2) \mathrm{i}}>\ldots>\mathrm{W}_{1 \mathrm{i}}$ as shown in Fig. 4. $W_{\text {. }}$ is the intermediate threshold value for $i^{\text {th }}$ degradation process. Fig. 4 demonstrates a sample degradation trend. As it is clearly observed, the degradation trend follows an accelerated strict-increasing pattern. Intervals are respectively corresponding to the intermediate degradation states as $\mathrm{M}_{\mathrm{i}},(\mathrm{M}-$ $1)_{\mathrm{i}}, \ldots, 1_{\mathrm{i}}, 0_{\mathrm{i}}$.

Mathematically, one can find the relationship between degradation process states and their corresponding intervals as expressed in eq. (1) as follows:

Effective degradation process State

$\begin{array}{lll}0<\mathrm{Y}_{\mathrm{i}}(\mathrm{t}) \leq \mathrm{W}_{\mathrm{Mi}} & \Rightarrow & \mathrm{M}_{\mathrm{i}} \\ \mathrm{W}_{\mathrm{Mi}}<\mathrm{Y}_{\mathrm{i}}(\mathrm{t}) \leq \mathrm{W}_{(\mathrm{M}-1) \mathrm{i}} & \Rightarrow & (\mathrm{M}-1)_{\mathrm{i}} \\ & \vdots & \\ \mathrm{W}_{2 \mathrm{i}}<\mathrm{Y}_{\mathrm{i}}(\mathrm{t}) \leq \mathrm{W}_{1 \mathrm{i}} & \Rightarrow & 1_{\mathrm{i}} \\ \mathrm{G}_{\mathrm{i}}=\mathrm{W}_{1 \mathrm{i}}<\mathrm{Y}_{\mathrm{i}}(\mathrm{t}) & \Rightarrow & 0_{\mathrm{i}}\end{array}$

\section{C.2 System State Space}

System state space is defined as $\boldsymbol{\Omega}_{\mathbf{U}}=\{\mathrm{M}, \ldots, 1,0, \mathrm{~F}\}$ considering $\mathrm{M}+2$ distinct states. In this section, a relationship between effective degradation processes $\left\{\boldsymbol{\Omega}_{\mathbf{i}}, \mathrm{F}\right\}, \mathrm{i}=0,1, \ldots, \mathrm{k}$ and the global system state space $\boldsymbol{\Omega}_{\mathbf{U}}$ will be established. It is assumed that the system is not in its catastrophic failure state (F) at the time $t$. Therefore, one can cross out the state $\mathrm{F}$ from global system state space. Thus, a correlation between $\boldsymbol{\Omega}$ and $\boldsymbol{\Omega}_{\mathbf{i}}$ is required instead of a correlation between $\boldsymbol{\Omega}_{\mathbf{U}}$ and $\left\{\boldsymbol{\Omega}_{\mathbf{i}}, F\right\}$, $\mathrm{i}=0,1, \ldots, \mathrm{k}$.

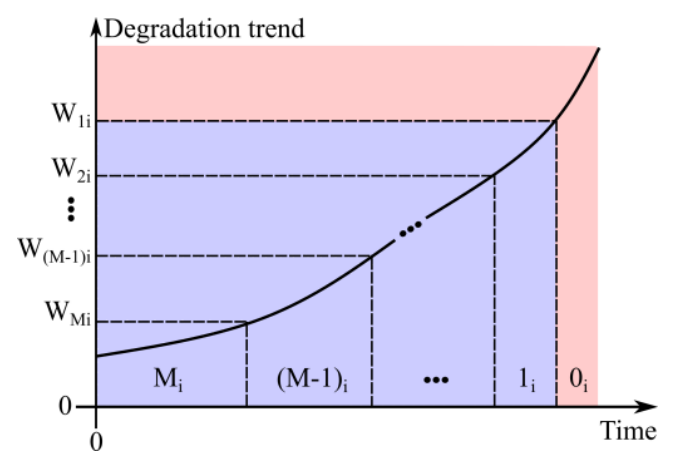

Fig. 4. Degradation process and states and their corresponding intervals. 
A mapping function has to be defined for relating these two different sets as f: $\mathbb{R}=\boldsymbol{\Omega}_{\mathbf{1}} \times \mathbf{\Omega}_{\mathbf{2}} \times \ldots \times \mathbf{\Omega}_{\mathbf{k}} \rightarrow \boldsymbol{\Omega}=\{\mathrm{M}, \mathrm{M}-1, \ldots, 1,0\}$ where $\mathbb{R}=\boldsymbol{\Omega}_{\mathbf{1}} \times \boldsymbol{\Omega}_{\mathbf{2}} \times \ldots \times \boldsymbol{\Omega}_{\mathbf{k}}=\left\{\left(\mathrm{i}_{1}, \mathrm{i}_{2}, \ldots, \mathrm{i}_{\mathrm{k}}\right) \mid \mathrm{i}_{1} \in \boldsymbol{\Omega}_{\mathbf{1}}, \mathrm{i}_{2} \in \boldsymbol{\Omega}_{\mathbf{2}}, \ldots, \mathrm{i}_{\mathrm{k}} \in \boldsymbol{\Omega}_{\mathbf{k}}\right\}$ is a Cartesian product as the input space domain, and shown in Fig. 5. The domain and the range of the mapping function has been indicated in Fig. 5a. $\mathrm{H}_{\mathrm{c}}$ is the mapping matrix with the dimensions of $\left(M_{1}+1\right) \times\left(M_{2}+1\right) \times \ldots \times\left(M_{k}+1\right)$ in which $M_{i}$ is the number of probable states for the $i^{\text {th }}$ effective items and $\mathrm{i}=0,1$, $\ldots, \mathrm{k}$. For example for $\mathrm{k}=3$, a 3 dimensional mapping matrix is required. Thereby, the first item constitutes the rows of the mapping matrix, the second one constitutes the column of mapping matrix and the third one constitutes the pages of the matrix as shown in Fig. 5b. Mapping matrix of $\mathrm{H}_{\mathrm{c}}$ has mapped the different input states to the specific output global states containing $\mathrm{M}+1$ distinct states.

While different rows of mapping matrix $\mathrm{H}_{\mathrm{c}}$ are allocated to different intermediate degradation states of the first item, different columns and pages are allocated to the second and the third items, respectively. The elements of $\mathrm{H}_{\mathrm{c}}$ represent $\mathrm{f}\left(\mathrm{i}_{1}, \mathrm{i}_{2}, \ldots, \mathrm{i}_{\mathrm{k}}\right)=\mathrm{P}$ in which $\mathrm{i}_{1} \in \boldsymbol{\Omega}_{\mathbf{1}}, \mathrm{i}_{2} \in \boldsymbol{\Omega}_{\mathbf{2}}, \ldots, \mathrm{i}_{\mathrm{k}} \in \boldsymbol{\Omega}_{\mathbf{k}}$ and $\mathrm{P} \in\{\mathrm{M}-1, \mathrm{M}-$ $2, \ldots, 1\}$. Regarding Fig. 5b, the first elements of mapping matrix $\mathrm{H}_{\mathrm{c}}$ in whole the matrix pages and the first column and the first row of the first mapping matrix page as well have been demonstrated by $\times$. These elements are not achievable, because if one of the items reaches its failure state $\left(0_{i}\right)$, the system stops working and necessarily the others cannot reach their failure states as well. All the other elements in the first page in which

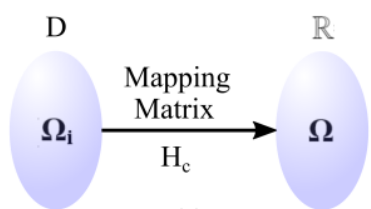

(a)

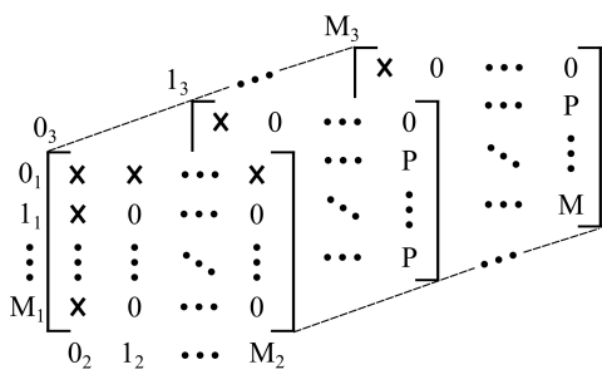

(b)

Fig. 5. Mapping Matrix. a) Each state of effective items is allocated to a specific global system state, b) Three-item mapping matrix $H_{c}$ where $P \in \Omega=\{M-1, M-2$, $\ldots, 1\}$.

the third element is in its failure state $\left(0_{3}\right)$ are equal to zero. In addition, for all the matrix pages, the first rows and the first columns (except the first element) are also zero due to the zero states of the first and the second items degradation states. The last element of mapping matrix $\mathrm{H}_{\mathrm{c}}$ is the perfect state of the global system (M) in which the system is initially in it because all the effective items are in their healthy (perfect) states. The other elements in $\mathrm{H}_{\mathrm{c}}$ are imperfect states belonging to the global state system $\boldsymbol{\Omega}$ except $\mathrm{M}$, namely global system perfect state. Some other elements also may be considered zero when the items are in their low states. It means that in the states in which some of the effective items are roughly degraded, one can define those states as global degraded states.
Time-to-failure of the global system is defined as follows:

$\mathrm{T}=\inf \left\{\mathrm{t}: \mathrm{Y}_{\mathrm{i}}(\mathrm{t})>\mathrm{G}_{\mathrm{i}}, \mathrm{i}=1,2, \ldots, \mathrm{k}\right.$ or $\left.\mathrm{F}_{\mathrm{j}}>\mathrm{B}_{\mathrm{S}_{\mathrm{j}}}, \mathrm{j}=1,2, \ldots, \ell\right\}$

All the degradation processes including effective and ineffective items are competing in the reliability of the global system. However, the global system will be failed provided that the only one of the degradation processes exceeds its critical value. Accordingly for all combinations of $Y_{i}(t), i=1,2, \ldots, k$ and also for all combinations of $\mathrm{D}_{\mathrm{j}}(\mathrm{t}), \mathrm{j}=1,2, \ldots, \ell$, following events never occurred:

$$
\begin{aligned}
& P\left\{\begin{array}{l}
Y_{i}(t)>G_{i}, \forall \bigcup_{i i=1}^{k, i i \neq i} Y_{i i}(t) \mid i=1,2, \ldots, k, \\
D_{j}(t)<B\left(S_{j}\right) \mid j=1,2, \ldots, 1
\end{array}\right\}=0 \\
& P\left\{\begin{array}{l}
Y_{i}(t)<G_{i} \mid i=1,2, \ldots, k, \\
D_{j}(t)>B\left(S_{j}\right), \forall \bigcup_{j j=1}^{k, j j \neq j} D_{j j}(t) \mid j=1,2, \ldots, 1
\end{array}\right\}=0 \\
& P\left\{\begin{array}{l}
Y_{i}(t)>G_{i}, \forall \bigcup_{i i=1}^{k, i i \neq i} Y_{i i}(t) \mid i=1,2, \ldots, k, \\
D_{j}(t)>B\left(S_{j}\right), \forall \bigcup_{j j=1}^{k, j j \neq j} D_{j j}(t) \mid j=1,2, \ldots, 1
\end{array}\right\}=0
\end{aligned}
$$

It means that if one of the effective or ineffective item reaches its failure state, the global system will fail and thereby the combination of the other items in their failure states will never happen. Thus, the probability of any combination of failure states of effective and ineffective items becomes zero.

The function f: $\mathbb{R}=\mathbf{\Omega}_{\mathbf{1}} \times \mathbf{\Omega}_{\mathbf{2}} \times \ldots \times \mathbf{\Omega}_{\mathbf{k}} \rightarrow \boldsymbol{\Omega}=\{\mathrm{M}, \mathrm{M}-1, \ldots, 1,0\}$ has to meet following requirements:

1. $f\left(M_{1}, M_{2}, \ldots, M_{k}\right)=M$ and $f\left(0_{1}, a_{2}, \ldots, a_{k}\right)=f\left(a_{1}, 0_{2}, \ldots, a_{k}\right)=$ $\mathrm{f}\left(\mathrm{a}_{1}, \mathrm{a}_{2}, \ldots, \mathrm{O}_{\mathrm{k}}\right)=0$ where $\mathrm{a}_{\mathrm{i}} \in \boldsymbol{\Omega}_{\mathbf{i}}, \mathrm{i}=1,2, \ldots, \mathrm{k}$.

2. $\mathrm{f}$ is a monotonic strictly non-decreasing function for each argument. For example,

$$
\begin{aligned}
& f\left(a_{1}, a_{2}, \ldots, a_{k}\right) \geq f\left(b_{1}, a_{2}, \ldots, a_{k}\right) \text { if } a_{1} \geq b_{1} \\
& f\left(a_{1}, a_{2}, \ldots, a_{k}\right) \geq f\left(a_{1}, b_{2}, \ldots, a_{k}\right) \text { if } a_{2} \geq b_{2} \\
& \vdots \\
& f\left(a_{1}, a_{2}, \ldots, a_{k}\right) \geq f\left(a_{1}, a_{2}, \ldots, b_{k}\right) \text { if } a_{k} \geq b_{k} \\
& \text { where } a_{i} \text { and } b_{i} \in \Omega_{i}, i=1,2, \ldots, k .
\end{aligned}
$$

In real applications, a different degradation state combination can generate the same outputs. Thereby, in the mapping matrix $\mathrm{H}_{c}$, there may be the same outputs in the different elements. Following definition has to be considered for explaining this similarity in the mapping matrix.

Definition. The $\mathrm{i}^{\text {th }}$ equivalent category $\mathrm{R}_{\mathrm{i}}$ is defined as

$\mathrm{R}_{\mathrm{m}}=\left\{\begin{array}{l}\left(\mathrm{a}_{1}, \mathrm{a}_{2}, \ldots, \mathrm{a}_{\mathrm{k}}\right) \text { where } \mathrm{a}_{1} \in \boldsymbol{\Omega}_{1}, \mathrm{a}_{2} \in \boldsymbol{\Omega}_{2} \\ , \ldots, \mathrm{a}_{\mathrm{k}} \in \boldsymbol{\Omega}_{\mathrm{k}} \mid \mathrm{f}\left(\mathrm{a}_{1}, \mathrm{a}_{2}, \ldots, \mathrm{a}_{\mathrm{k}}\right)=\mathrm{m}\end{array}\right\}, \mathrm{m}=0,1, \ldots, \mathrm{M}$

where $R_{m}$ demonstrates all the possible degradation state combinations which generate the global system state $\mathrm{m}$, and $\mathrm{R}_{0}$ and $R_{M}$ are the distinct subsets dividing $R$ to the $M+1$ equivalent categories, so that:

$$
R=\bigcup_{m=0}^{M} R_{i}
$$

\section{Reliability Assessment}

In this section, the probability density function and mean time to failure will be obtained on the state probabilities mentioned in section 2.C. Initially, the global system is 
considered to be in its perfect state, i.e. $M=f\left(R_{M}\right)$. The probability of being in state $M$ yields by:

$$
\mathrm{P}_{\mathrm{t}}(\mathrm{M})=\mathrm{P}_{\mathrm{t}}\left(\mathrm{f}\left(\mathrm{R}_{\mathrm{M}}\right)\right)
$$

As defined, $R_{m}$ illustrates all possible degradation state combinations leading to the global system state of $\mathrm{m}$. The probability of being in state $m$ yields by:

$$
\mathrm{P}_{\mathrm{t}}(\mathrm{m})=\mathrm{P}\left(\mathrm{f}\left(\mathrm{R}_{\mathrm{m}}\right)\right)
$$
by

The probability of catastrophic failure state $(\mathrm{F})$ is evaluated $P_{t}(F)=P\left\{Y_{i}(t) \leq G_{i}\left|i=1,2, \ldots, k, D_{j}(t) \geq B\left(S_{j}\right)\right| j=1,2, \ldots, 1\right\}(9)$

The system reliability $\mathrm{R}(\mathrm{t})$ can be assessed by

$$
\mathrm{R}(\mathrm{t})=\mathrm{P}\{\text { global system state } \geq 1\}=\bigcup_{\mathrm{m}=1}^{\mathrm{M}} \mathrm{P}\left\{\mathrm{f}\left(\mathrm{R}_{\mathrm{m}}\right)\right\}=\sum_{\mathrm{m}=1}^{\mathrm{M}} \mathrm{P}_{\mathrm{t}}(\mathrm{m})
$$

where $P_{t}(m)$ is the probability of being in the global system state of $\mathrm{m}$.

Assuming $\mathrm{T}$ as a continuous random variable of mean time to failure, one can calculate the mean time to failure as follows:

$$
\mathrm{E}[\mathrm{T}]=\int_{0}^{\infty}\left\{\prod_{\mathrm{i}=1}^{\mathrm{k}} \mathrm{P}\left\{\mathrm{Y}_{\mathrm{i}}(\mathrm{t}) \leq \mathrm{G}_{\mathrm{i}}\right\} \times \prod_{\mathrm{j}=1}^{\ell}\left(\mathrm{F}_{\mathrm{j}}(\eta, \beta)<\mathrm{B}\left(\mathrm{S}_{\mathrm{j}}\right)\right)\right\} \mathrm{dt}
$$

where $F_{j}$ is the probability function of $j^{\text {th }}$ ineffective item. The results in (11) would strongly depend on the first term in integration, i.e. effective degradation processes.

\section{ApPliCAtion to POWER EleCtRONIC SyStEMS}

In this section, we consider a power electronic system, containing various components individually confronted to different failure mechanisms. Every component has effects on the system operating conditions during its working. It has been proved that the components' degradations can extensively be effective in power electronic systems' operating points [25]. A power electronic system contains various components which each of them may be sensitive to the various failure mechanisms leading to aging (parameter drifting). Among all the power electronic components, power semiconductors and capacitors as well are both said to be the critical components as a reliability point of view [26].

In addition, it is notable that power semiconductors' degradations can strongly affect the power electronic systems' electrical and thermal operating points. It was illustrated in [25] that the junction temperature of insulated-gate bipolar transistor (IGBT) was increased from $140.3^{\circ} \mathrm{C}$ to $170.5^{\circ} \mathrm{C}$ during the aging which significantly affected the operating points of the system. However, it was not the case in the power capacitor's degradation. During capacitor aging, its parameters were considerably varied but these parameters drifting did not lead to an operating point change [25]. Although, reliability of capacitors, thereby, would be considered here, power capacitors' failure mechanisms are beyond this study and the interested readers can refer to [27].

\section{A. Failure mechanisms of power semiconductors}

Regarding the critical stressors (steady state temperature and temperature swing), two most critical failure mechanisms are electro thermo mechanical fatigue and creep [28]-[30]. Regarding physical structure of power semiconductors comprising various layers with different coefficients of thermal expansion (CTE), a meaningful set of shear and normal stresses are induced in these layers [28]. Thereby, electro-thermomechanical stresses have been occurred during the power semiconductor operations leading to the plastic and elastic strains through the bodies and eventually either producing some micro cracks and micro voids or growing pre-induced micro cracks and micro voids. The creep and creep-fatigue failures are the events activated with the rise in temperature above the onethird of melting point of metals [30]. The mentioned events are intensified upon passing of the time, when high temperature induces viscous effects to the materials. The evolution of creep damage includes the formation and growth of micro-voids, micro-crack formation at inter-granular sites and their coalescence in the crystals triple points [31], [32].

\section{B. Failure indicator of power semiconductors}

Parameters drifting (due to degradation) plays a major role in the failure definition. In the literature, several parameters drifting have been reported [29]. However, thermal resistance $\left(\mathrm{R}_{\mathrm{th}}\right)$ is a common parameter drifting in power semiconductors and can affect device performance significantly during its aging [29].

As previously mentioned, die attach degradation is illustrated by crack growth and void coalescence in the solder joint. Elasto-visco-plasticitic strain in the solder joint owing to creepfatigue failure mechanisms is the main factor in the die attach deterioration [33]. Since Coffin-Manson-Arrhenius lifetime model [34], [35] has been widely employed for lifetime estimation, thermal resistance degradation processes may be expressed as follow [33]:

$$
\Delta \mathrm{R}_{\mathrm{th}}=\mathrm{K}\left\{\exp \left(\frac{\mathrm{N}}{\mathrm{A} \times \Delta \mathrm{T}_{\mathrm{j}}^{\alpha} \times \exp \left(\mathrm{Q} / \mathrm{RT}_{\mathrm{m}}\right)}\right)-1\right\}
$$

where $\mathrm{A}, \alpha$ and $\mathrm{K}$ are both constant and device-dependent, $\mathrm{R}$ and $\mathrm{Q}$ are the gas constant $\left(8.314 \mathrm{JMol}^{-1} \mathrm{~K}^{-1}\right)$, internal energy and $\mathrm{T}_{\mathrm{m}}$ is the mean junction temperature of devices in Kelvin. $\Delta \mathrm{T}_{\mathrm{j}}$ expresses the junction temperature swing of devices in ${ }^{\circ} \mathrm{C}$. $\mathrm{N}$ is the number of cycles applied to the power semiconductors. The deterioration trend of thermal resistances, in the two mostly applied power semiconductors i.e. IGBT and diode, was extracted from accelerated power cycling (APC) aging test and is shown in Fig. 6. This figure demonstrates the deterioration trends of thermal resistances of power diode and IGBT as a function of thermal cycles.

\section{Experimental procedure}

In this setup, a power current is periodically injected into the device under test (DUT) and thereby a junction temperature swing $(\Delta T)$ is induced in the chip. Every heating up and cooling down in the junction of DUT has been defined as a distinct one power cycle. APC is continued till the failure indicators reach the defined failure criteria. The number of cycles before fulfilment of the failure criteria has been considered as a number of cycles to failure $\left(\mathrm{N}_{\mathrm{F}}\right)$ for different temperature swing and mean temperature levels.

JESD22-A105C, JESD22-A122A, JESD22-A104E, JESD6- 
-59B and JESD91A are the most well-known APC testing standards. But, they have never gone into much detail of circuit design regarding different applications and various failure mechanisms. That is why various studies have been under taken by proposing their customized APC tests [35]-[38].

For obtaining the degradation processes of IGBT and power diodes, a conventional accelerated aging test has been done. In this case, IGBT and diode were exposed to cyclic thermal variations. In this study, accelerated power cycling aging test was employed by injecting a constant current into the IGBT and power diode. Under studied devices were $600 \mathrm{~V}-15 \mathrm{~A}$ IGBT and internal power diode of Infineon components, namely IKP15N60T. It has been reported that solder layer degradation is the most probable failure site in power semiconductors [28], [29].

In this test, there were 8 different conditions (different mean temperatures and temperature swings) for IGBT and power diodes. For each of them, there were 4 diodes and IGBTs for making the results much more accurate and reliable. Therefore, 32 IGBTs and 32 diodes were under the test.

For avoiding catastrophic failure and changes in failure mechanism, the maximum current of $15 \mathrm{~A}$ was injected into the devices. This current injection led to a conduction power loss in the device which was finally leading to a temperature rise in the devices' dies. It led to a maximum temperature $\left(\mathrm{T}_{\mathrm{jmax}}\right)$. It should be noted that the devices were mounted on a cold plate with fixed temperature. Therefore, after stopping current injection, the temperature of devices decreases to the temperature of cold plate $\left(\mathrm{T}_{\mathrm{jmin}}\right)$. The relaxing time for the devices was much more to make sure that the devices' junction temperatures have reached $\mathrm{T}_{\mathrm{jmin}}$. This accelerated power cycling test had continued until device reached its failure criteria.

APC tests were performed for various mean temperatures and temperature swings for both IGBT and power diodes. 130, 110,90 and $70^{\circ} \mathrm{C}$ temperature swing for mean temperature of $105^{\circ} \mathrm{C}$ and 110,70 and $70^{\circ} \mathrm{C}$ for mean temperature of $95^{\circ} \mathrm{C}$ were the different conditions of APC tests for preparing number of cycle to failure degradation model (see Fig. 6).

\section{RESUlTS AND DisCUSSIONS}

In this section, APC results (degradation processes of IGBT and diode) are illustrated and discussed. In addition, the newly proposed reliability assessment method is applied to a specific power electronic converter as a case study in the hybrid electric vehicle as an interface between battery bank and driving system exposed to WLTP-class 3 driving cycle.

\section{A. APC test results}

Table 1 and Table 2 list the results of power cycling accelerated tests. In this power cycling tests, junction to case thermal resistance (as the failure indicator) had been evaluated through thermo sensitive electrical parameter. It has to be mentioned that during these tests, junction to case thermal resistance exceeded the failure criterion (20\% increase) [25]. It stands to reason that by solder degradation (producing voids and cracks), an increase in the junction to case thermal resistance has been led. Regarding Table 1 and 2, the higher mean temperature and temperature swing, the lower number of cycles to failure. It is worthy to mention that for each condition, four different IGBTs/diodes had been under the test. B4 and D4 were not accessible (NA) and achieved owing to the low temperature swing during the test.
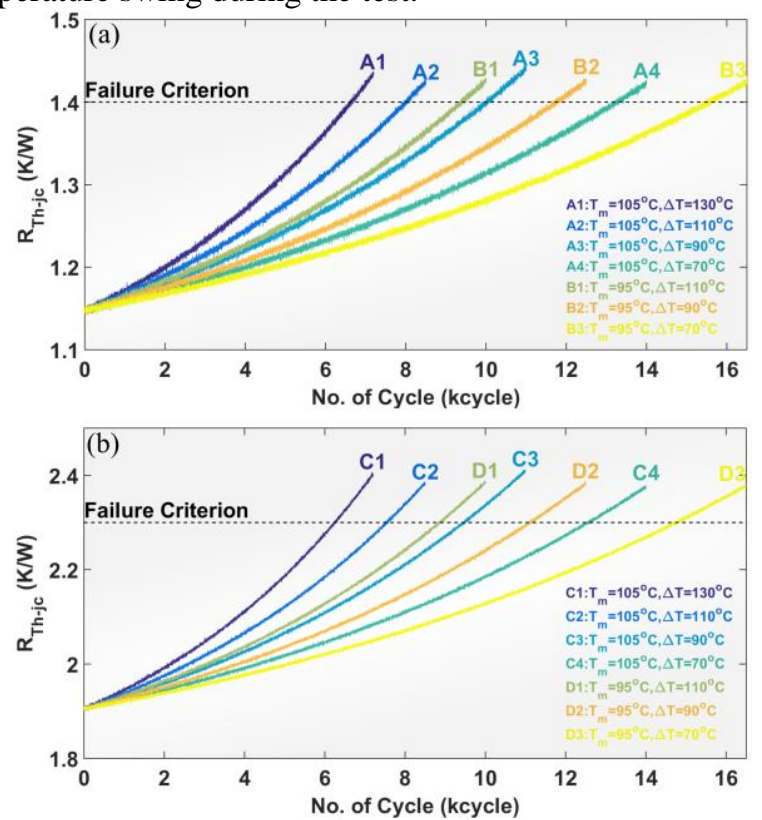

Fig. 6. Deterioration trends of power semiconductors against various thermal cycles. a) Power IGBT, b) Power diode.

\section{B. Reliability assessment}

The analysis procedure applying to this case study is based on Fig. 2 and the materials explained in section II.

1-Component type determination: a power converter containing two critical effective components, namely IGBT and power diode, and one critical ineffective component, namely power capacitors, has been assumed. There are three distinct items as system reliability point of view in which the system would be failed provided that one of these items is being failed. Power capacitor is considered as an ineffective item with $\mathrm{D}(\mathrm{t})$ time to failure distribution following Weibull damage model $(\mathrm{D}(\mathrm{t}) \sim \mathrm{W}(\eta, \beta)$ where $\eta$ and $\beta$ are the scale factor and shape factor, respectively).

2-Degradation processes of effective items: the degradation trends of the effective items have to be considered based on the mission profile which the system/items are exposed to. The degradation processes of IGBT and power diode are considered as a function of time and denoted by $Y_{1}(t)$ and $Y_{2}(t)$, respectively. The degradation trends of IGBT and power diode in four different conditions have been shown in Fig. 6. These trends have been in terms of thermal cycles while they have to be in terms of time for reliability assessment. Accordingly, WLTP-class 3 driving cycle mission profile has been translated from the vehicle speed to the thermal cycling data via power electronic electrical model, power loss model and thermal model [25]. Then this set of complex data has been inserted to the rain flow algorithm [30] to be sorted. Finally, this set of sorted data has been applied to the Coffin-Manson-Arrhenius lifetime model (equation (12)) for evaluating the degradation processes as a function of time. Based on the aforementioned 
procedure, one can obtain time-dependent degradation paths of IGBT and power diode as follows:

$$
\mathrm{Y}_{1}(\mathrm{t})= \begin{cases}1.1500+2.246 \times 10^{-6} \mathrm{t} & 0<\mathrm{t}<25602 \text { hours } \\ 1.2075+2.438 \times 10^{-6} \mathrm{t} & 25602<\mathrm{t}<49194 \text { hours } \\ 1.2650+2.562 \times 10^{-6} \mathrm{t} & 49194<\mathrm{t}<71634 \text { hours } \\ 1.3225+2.812 \times 10^{-6} \mathrm{t} & 71634<\mathrm{t}<92082 \text { hours }\end{cases}
$$

And

$$
\mathrm{Y}_{2}(\mathrm{t})= \begin{cases}1.900+7.124 \times 10^{-6} \mathrm{t} & 0<\mathrm{t}<13336 \text { hours } \\ 1.995+7.189 \times 10^{-6} \mathrm{t} & 13336<\mathrm{t}<26552 \text { hours } \\ 2.090+7.670 \times 10^{-6} \mathrm{t} & 26552<\mathrm{t}<38912 \text { hours } \\ 2.185+7.740 \times 10^{-6} \mathrm{t} & 38912<\mathrm{t}<51192 \text { hours }\end{cases}
$$

Regarding above mentioned equation, one can find the accelerating degradation of power semiconductors, i.e. IGBT and power diode. Each of the constant in equation (13) is assumed to be normally distributed with $5 \%$ variation for considering uncertainties. Fig. 7 demonstrates the degradation rends of IGBT and power diode and their corresponding degradation states.

3-Defining effective items' state spaces: the power converter has two effective degradation processes. For each of them, five different discrete states have been also taken into account. Their state spaces are denoted by $\boldsymbol{\Omega}_{\mathbf{1}}=\left\{4_{1}, 3_{1}, 2_{1}, 1_{1}, 0_{1}\right\}$ and $\boldsymbol{\Omega}_{\mathbf{2}}=\left\{4_{2}\right.$, $\left.3_{2}, 2_{2}, 1_{2}, 0_{2}\right\}$. The perfect states of them are $4_{1}$ and $4_{2}$ and the failure states are $0_{1}$ and $0_{2}$. Accordingly, once either IGBT and power diode reach their zero states, the system is failed.

4-Defining effective items' intervals corresponded to their state spaces: $\mathrm{Y}_{1}(\mathrm{t})$ and $\mathrm{Y}_{2}(\mathrm{t})$ fall into predefined intervals corresponding to their five intermediate degradation states. Since $20 \%$ increase in the junction to case thermal resistance has been considered as the failure criterion, $5 \%$ step increase in the junction to case thermal resistance is considered for discretizing the degradation trend to five intermediate states for
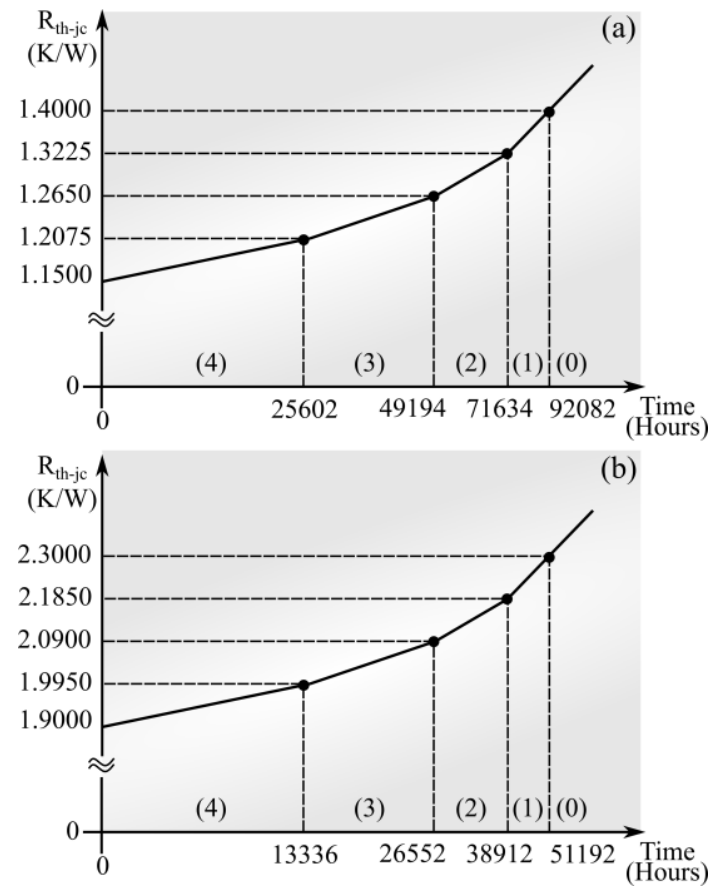

Fig. 7. Degradation processes of a) IGBT and b) power diode.
Table 1. IGBT number of cycle to failure for power cycling accelerated test

\begin{tabular}{ccccc}
\hline Test code & $\begin{array}{c}\text { Temperature } \\
\text { swing }\left({ }^{\circ} \mathrm{C}\right)\end{array}$ & $\begin{array}{c}\mathrm{T}_{\text {mean }} \\
\left({ }^{\circ} \mathrm{C}\right)\end{array}$ & $\begin{array}{c}\Delta \mathrm{T} \\
\left({ }^{\circ} \mathrm{C}\right)\end{array}$ & $\begin{array}{c}\text { Mean number of } \\
\text { Cycles to Failure }\end{array}$ \\
\hline \hline $\mathrm{A} 1$ & $40-170$ & & 130 & 6853 \\
$\mathrm{~A} 2$ & $50-160$ & 105 & 110 & 8303 \\
$\mathrm{~A} 3$ & $60-150$ & & 90 & 10212 \\
$\mathrm{~A} 4$ & $70-140$ & & 70 & 13820 \\
\hline $\mathrm{B} 1$ & $40-150$ & & 110 & 9825 \\
$\mathrm{~B} 2$ & $50-140$ & 95 & 90 & 12233 \\
$\mathrm{~B} 3$ & $60-130$ & & 70 & 16102 \\
$\mathrm{~B} 4$ & $70-120$ & & 50 & $\mathrm{NA}$ \\
\hline
\end{tabular}

Table 2. Diode number of cycle to failure for power cycling accelerated test

\begin{tabular}{ccccc}
\hline Test code & $\begin{array}{c}\text { Temperature } \\
\text { swing }\left({ }^{\circ} \mathrm{C}\right)\end{array}$ & $\begin{array}{c}\mathrm{T}_{\text {mean }} \\
\left({ }^{\circ} \mathrm{C}\right)\end{array}$ & $\begin{array}{c}\Delta \mathrm{T} \\
\left({ }^{\circ} \mathrm{C}\right)\end{array}$ & $\begin{array}{c}\text { Mean number of } \\
\text { Cycles to Failure }\end{array}$ \\
\hline \hline C1 & $40-170$ & & 130 & 6266 \\
$\mathrm{C} 2$ & $50-160$ & \multirow{2}{*}{105} & 110 & 7603 \\
$\mathrm{C} 3$ & $60-150$ & & 90 & 9625 \\
$\mathrm{C} 4$ & $70-140$ & & 70 & 12006 \\
\hline D1 & $40-150$ & & 110 & 9051 \\
D2 & $50-140$ & & 90 & 11208 \\
D3 & $60-130$ & 95 & 70 & 14864 \\
D4 & $70-120$ & & 50 & NA \\
\hline
\end{tabular}

both IGBT and power diode. Let consider the intervals as follows: $\{[1,1.05],(1.05,1.1],(1.1,1.15],(1.15,1.2]$, (1.2, $\infty)\} \times \mathrm{R}_{\text {th_nominal. }}$ Nominal junction to case thermal resistances of IGBT and diode are $1.16^{\circ} \mathrm{C} / \mathrm{W}$ and $1.9^{\circ} \mathrm{C} / \mathrm{W}$, respectively. Therefore,

$\begin{array}{lll}0<\mathrm{Y}_{1}(\mathrm{t}) \leq 1.2075 & \Rightarrow & 4_{1} \\ 1.2075<\mathrm{Y}_{1}(\mathrm{t}) \leq 1.265 & \Rightarrow & 3_{1} \\ 1.265<\mathrm{Y}_{1}(\mathrm{t}) \leq 1.3225 & \Rightarrow & 2_{1} \\ 1.3225<\mathrm{Y}_{1}(\mathrm{t}) \leq 1.4 & \Rightarrow & 1_{1} \\ \mathrm{G}_{1}=1.4<\mathrm{Y}_{1}(\mathrm{t}) & \Rightarrow & 0_{1} \\ \text { And } & & \\ 0<\mathrm{Y}_{2}(\mathrm{t}) \leq 1.995 & \Rightarrow & 4_{2} \\ 1.995<\mathrm{Y}_{2}(\mathrm{t}) \leq 2.09 & \Rightarrow & 3_{2} \\ 2.09<\mathrm{Y}_{2}(\mathrm{t}) \leq 2.185 & \Rightarrow & 2_{2} \\ 2.185<\mathrm{Y}_{2}(\mathrm{t}) \leq 2.3 & \Rightarrow & 1_{2} \\ \mathrm{G}_{2}=2.3<\mathrm{Y}_{2}(\mathrm{t}) & \Rightarrow & 0_{2}\end{array}$

5-Defining system state space and mapping matrix: the power system state space is assumed as $\mathbf{\Omega}_{\mathbf{U}}=\{4,3,2,1,0, \mathrm{~F}\}$ consisting 6 distinct states. Assuming that at the time t, the system is not in its catastrophic failure state $(\mathrm{F})$, one can assume $\boldsymbol{\Omega}=\{4,3,2$, $1,0\}$ instead of $\boldsymbol{\Omega}_{\mathbf{U}}$. Mapping matrix of following equation is also assumed:

$$
\begin{aligned}
& \begin{array}{lllll}
0_{2} & 1_{2} & 2 & 3 & 3_{2}
\end{array} \\
& 0_{1}\left[\begin{array}{ccccc}
\times & 0 & 0 & 0 & 0
\end{array}\right. \\
& 1_{1} \mid \begin{array}{lllll}
0 & 0 & 1 & 1 & 1
\end{array} \\
& \mathrm{H}_{\mathrm{c}}=2_{1} \mid \begin{array}{lllll}
0 & 1 & 2 & 2 & 2
\end{array} \\
& 3_{1} \mid \begin{array}{lllll}
0 & 1 & 2 & 3 & 3
\end{array} \\
& 4_{1}\left[\begin{array}{lllll}
0 & 1 & 2 & 3 & 4
\end{array}\right]
\end{aligned}
$$

Accordingly, one can numerate $\mathrm{R}$ as

$$
\left\{\begin{array}{l}
\left(0_{1}, 1_{2}\right),\left(0_{1}, 2_{2}\right),\left(0_{1}, 3_{2}\right),\left(0_{1}, 4_{2}\right),\left(1_{1}, 0_{2}\right),\left(1_{1}, 1_{2}\right), \\
\left(1_{1}, 2_{2}\right),\left(1_{1}, 3_{2}\right),\left(1_{1}, 4_{2}\right),\left(2_{1}, 0_{2}\right),\left(2_{1}, 1_{2}\right),\left(2_{1}, 2_{2}\right), \\
\left(2_{1}, 3_{2}\right),\left(2_{1}, 4_{2}\right),\left(3_{1}, 0_{2}\right),\left(3_{1}, 1_{2}\right),\left(3_{1}, 2_{2}\right),\left(3_{1}, 3_{2}\right), \\
\left(3_{1}, 4_{2}\right),\left(4_{1}, 0_{2}\right),\left(4_{1}, 1_{2}\right),\left(4_{1}, 2_{2}\right),\left(4_{1}, 3_{2}\right)\left(4_{1}, 4_{2}\right)
\end{array}\right\}
$$


Regarding $\mathrm{H}_{\mathrm{c}}$ and the global system state space, there are five different categories as follows

$$
\begin{aligned}
& \mathrm{R}_{0}=\left\{\begin{array}{l}
\left(0_{1}, 1_{2}\right),\left(0_{1}, 2_{2}\right),\left(0_{1}, 3_{2}\right),\left(0_{1}, 4_{2}\right),\left(1_{1}, 0_{2}\right), \\
\left(2_{1}, 0_{2}\right),\left(3_{1}, 0_{2}\right),\left(4_{1}, 0_{2}\right),\left(1_{1}, 1_{2}\right)
\end{array}\right\} \\
& \mathrm{R}_{1}=\left\{\left(1_{1}, 2_{2}\right),\left(1_{1}, 3_{2}\right),\left(1_{1}, 4_{2}\right),\left(2_{1}, 1_{2}\right),\left(3_{1}, 1_{2}\right),\left(4_{1}, 1_{2}\right)\right\} \\
& \mathrm{R}_{2}=\left\{\left(2_{1}, 2_{2}\right),\left(2_{1}, 3_{2}\right),\left(2_{1}, 4_{2}\right),\left(3_{1}, 2_{2}\right),\left(3_{1}, 4_{2}\right)\right\} \\
& \mathrm{R}_{3}=\left\{\left(3_{1}, 3_{2}\right),\left(3_{1}, 4_{2}\right),\left(4_{1}, 3_{2}\right)\right\} \\
& \mathrm{R}_{4}=\left\{\left(4_{1}, 4_{2}\right)\right\} \\
& \mathrm{R}=\bigcup_{\mathrm{m}=0}^{4} \mathrm{R}_{\mathrm{i}}
\end{aligned}
$$

It is seen from equations (16) and (17) that the function which is in charge of mapping items' degradation states to the global system state space is a monotonic non-decreasing function. It means that if the degradation states of effective items or their combinations thereof decrease, the degradation states of the global system also either decreases or is equal to its previous state. As an example, $\mathrm{f}\left(4_{1}, 4_{2}\right)$ is greater than $\mathrm{f}\left(3_{1}, 4_{2}\right), \mathrm{f}\left(4_{1}, 3_{2}\right)$ and $\mathrm{f}\left(3_{1}, 3_{2}\right)$ :

$$
\mathrm{f}\left(4_{1}, 4_{2}\right)=4>\mathrm{f}\left(3_{1}, 4_{2}\right)=\mathrm{f}\left(4_{1}, 3_{2}\right)=\mathrm{f}\left(3_{1}, 3_{2}\right)=3
$$

6-Reliability assessment of by estimating non-failure states' probabilities: In this case study, power capacitor is considered as an ineffective item with following time to failure distribution [40]:

$$
\mathrm{D}(\mathrm{t} ; \eta, \beta) \sim \mathrm{W}(1471680,1.93)
$$

Power capacitors has been assumed to be failed whenever its unreliability reach $10 \%\left(\mathrm{~B}_{10}\right)$. The probability density function and mean time to failure will be obtained on the state probabilities mentioned. The probability of being in state $M=4$ would be calculated as follows:

$$
\begin{aligned}
\mathrm{P}_{\mathrm{t}}(4)=\mathrm{P}\left(\mathrm{f}\left(\mathrm{R}_{4}\right)\right)= & \mathrm{P}\left(0<\mathrm{Y}_{1}(\mathrm{t})<\mathrm{W}_{4_{1}} \cap 0<\mathrm{Y}_{2}(\mathrm{t})<\mathrm{W}_{4_{2}}\right) \\
& \times \mathrm{P}\left(\mathrm{D}(\mathrm{t})<\mathrm{B}_{10}\right)
\end{aligned}
$$

Since the degradation processes are assumed to be independent, one can find that

$$
\begin{aligned}
\mathrm{P}_{\mathrm{t}}(4)= & \mathrm{P}\left(0<\mathrm{Y}_{1}(\mathrm{t})<\mathrm{W}_{4_{1}}\right) \times \mathrm{P}\left(0<\mathrm{Y}_{2}(\mathrm{t})<\mathrm{W}_{4_{2}}\right) \\
= & \left\{\mathrm{P}\left(\mathrm{Y}_{1}(\mathrm{t})<\mathrm{W}_{4_{1}}\right)-\mathrm{P}\left(\mathrm{Y}_{1}(\mathrm{t})<0\right)\right\} \times \\
& \left\{\mathrm{P}\left(\mathrm{Y}_{2}(\mathrm{t})<\mathrm{W}_{4_{2}}\right)-\mathrm{P}\left(\mathrm{Y}_{2}(\mathrm{t})<0\right)\right\} \times \\
& (1-\mathrm{F}(\mathrm{t} ; \eta, \beta))
\end{aligned}
$$

Where $\mathrm{W}_{41}$ and $\mathrm{W}_{42}$ are threshold values of the fourth intermediate state and are 1.2075 and $1.995^{\circ} \mathrm{C} / \mathrm{W}$, respectively. Since $\mathrm{Y}_{\mathrm{i}}(\mathrm{t})=\mathrm{a}_{\mathrm{i}}+\mathrm{b}_{\mathrm{i}} \mathrm{t}$ where $\mathrm{a}_{\mathrm{i}} \sim \mathrm{N}\left(\mu_{\mathrm{ai}}, \sigma_{\mathrm{ai}}{ }^{2}\right)$ and $\mathrm{b}_{\mathrm{i}} \sim \mathrm{N}\left(\mu_{\mathrm{bi}}, \sigma_{\mathrm{bi}}{ }^{2}\right), \mathrm{Y}_{\mathrm{i}}(\mathrm{t})$ will follow normal distribution as follows:

$$
\begin{aligned}
& Y_{\mathrm{i}}(\mathrm{t}) \sim \mathrm{N}\left(\mu_{\mathrm{ai}}+\mu_{\mathrm{bi}} \mathrm{t}, \sigma_{\mathrm{ai}}^{2}+\mathrm{t}^{2} \sigma_{\mathrm{bi}}^{2}\right) ; \quad \mathrm{i}=1,2 \\
& \mu_{\mathrm{i}}=\mu_{\mathrm{ai}}+\mu_{\mathrm{bi}} \mathrm{t} \\
& \sigma_{\mathrm{i}}=\sigma_{\mathrm{ai}}^{2}+\mathrm{t}^{2} \sigma_{\mathrm{bi}}^{2}
\end{aligned}
$$

Therefore, one can calculate equation (22) as follows:

$$
\mathrm{P}_{\mathrm{t}}(4)=\Phi\left(\frac{\mathrm{W}_{4_{1}}-\mu_{1}}{\sigma_{1}}\right) \times \Phi\left(\frac{\mathrm{W}_{4_{2}}-\mu_{2}}{\sigma_{2}}\right) \times(1-\mathrm{F}(\mathrm{t} ; \eta, \beta))
$$

The other system states probablities can also be estimated in the same procedure described in (19)-(22). Fig. 8 illustrates the reliability of the different system states. Since the coefficients have been assumed to be normally distributed, the system probability is also normally distributed. The yellow curve shows the reliability of the global system. $10 \%$ unreliability or $90 \%$ reliability $\left(\mathrm{B}_{10}\right)$ is achieved at 58040 hours. Accordingly, the power electronic system may work over 58040 with $90 \%$ reliability. Based on the conventional PoF based reliability assessment approach, the reliability of this system is about 66680 hours. It means that by considering mutual and selfdegradation effects, the reliability evaluation of the system is much more realistic.

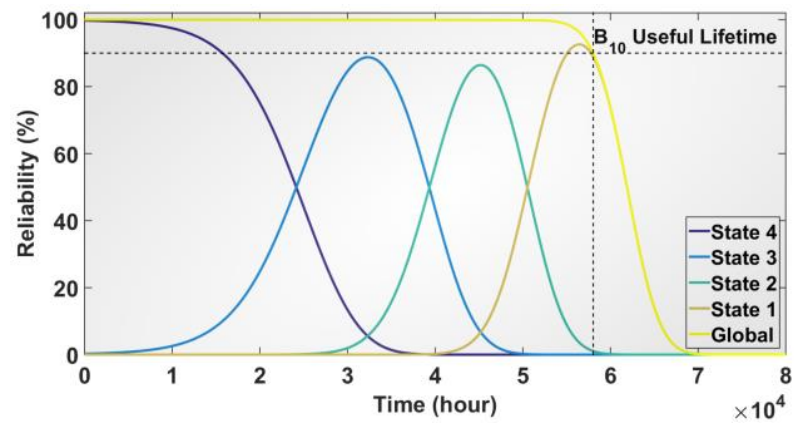

Fig. 8. Reliability functions.

\section{CONCLUSION}

In this paper, a new reliability assessment framework has been proposed. Based on this method, operating condition of a system has been characterized by a finite number of degraded states. This leads to the consideration of the dependancy of components' aging on the operating condition which finally leads to much more realistic reliability assessment.

The items of a system have been categorized into two different items, effective and ineffective items. Effective items are those which directly affect the operating condition of the system. While, ineffective items do not make meaningful contribution on the operating condition of the system and their failures lead to the catastrophic failure of the systems. Degradation processes of the effective items have been extracted from the mission profile based on aging tests and have been divided intoseveral intermediate degraded states. The various combinations of the effective items' states have been mapped to the global system states using a mapping matrix.

The proposed framework has been applied to a power electronic system containing two effective components, namely IGBT and diode, and one ineffective item, namely power capacitor. Mission profile based aging tests have been performed to study the degradation processes of IGBT and power diode. The results showed that the power electronic system which was exposed to the WLTP-class3 driving cycle might work over 58040 hours by $90 \%$ reliability.

An experimental work must be planned in the future to validate the estimated lifetimes using the proposed method. However, using the present results, it appears from this paper that it is very important to take into account the degradation dependencies for calculating the life time of power electronic converters. This new method could be a good option to answer this issue. 


\section{REFERENCES}

D. Zhou, Y. Song, Y. Liu, and F. Blaabjerg, "Mission Profile Based Reliability Evaluation of Capacitor Banks in Wind Power Converters," IEEE Trans. Power Electron., vol. 34, no. 5, pp. 46654677, 2019.

[2] S. Ashrafi and S. Zarezadeh, "A Shock-Based Model for the Reliability of Three-State Networks," IEEE Trans. Reliab., vol. 67, no. 1, pp. 274-284, 2018.

[3] Y.-H. Lin, Y.-F. Li, and E. Zio, "A comparison between Monte Carlo simulation and finite-volume scheme for reliability assessment of multi-state physics systems," Reliab. Eng. Syst. Saf., vol. 174, pp. 1$11,2018$.

[4] M. Andresen, K. Ma, G. Buticchi, J. Falck, F. Blaabjerg, and M. Liserre, "Junction Temperature Control for More Reliable Power Electronics," IEEE Trans. Power Electron., vol. 33, no. 1, pp. 765776, 2018.

F. Blaabjerg, D. Zhou, A. Sangwongwanich, and H. Wang, "Design for reliability in renewable energy systems," in 2017 International Symposium on Power Electronics (Ee), 2017, pp. 1-6.

[6] Y. Hu, Y. Ding, F. Wen, and L. Liu, "Reliability Assessment in Distributed Multi-State Series-Parallel Systems," Energy Procedia, vol. 159, pp. 104-110, 2019.

[7] W. Dong, S. Liu, L. Tao, Y. Cao, and Z. Fang, "Reliability variation of multi-state components with inertial effect of deteriorating output performances," Reliab. Eng. Syst. Saf., vol. 186, pp. 176-185, 2019.

[8] W. Li and M. J. Zuo, "Reliability evaluation of multi-state weighted k-out-of-n systems," Reliab. Eng. Syst. Saf., vol. 93, no. 1, pp. 160 167, 2008

[9] S. Eryilmaz, "A reliability model for a three-state degraded system having random degradation rates," Reliab. Eng. Syst. Saf., vol. 156, pp. 59-63, 2016 .

[10] Y. Sun, T. Sun, M. G. Pecht, and C. Yu, "Computing Lifetime Distributions and Reliability for Systems With Outsourced Components: A Case Study," IEEE Access, vol. 6, pp. 31359-31366, 2018.

[11] Y. Liu and C. Chen, "Dynamic Reliability Assessment for Nonrepairable Multistate Systems by Aggregating Multilevel Imperfect Inspection Data," IEEE Trans. Reliab., vol. 66, no. 2, pp. 281-297, 2017.

[12] V. Kumar, L. Singh, and A. K. Tripathi, "Reliability analysis of safety-critical and control systems: a state-of-the-art review," IET Softw., vol. 12, no. 1, pp. 1-18, 2018.

[13] Y. Liu, Y. Chen, and T. Jiang, "On sequence planning for selective maintenance of multi-state systems under stochastic maintenance durations," Eur. J. Oper. Res., vol. 268, no. 1, pp. 113-127, 2018.

[14] X. Zhao, S. Wang, X. Wang, and K. Cai, "A multi-state shock model with mutative failure patterns," Reliab. Eng. Syst. Saf., vol. 178, pp. $1-11,2018$.

[15] Y.-H. Lin, Y.-F. Li, and E. Zio, "Reliability Assessment of Systems with Dependent Degradation Processes Based on PiecewiseDeterministic Markov Process BT - Recent Advances in Multi-state Systems Reliability: Theory and Applications," A. Lisnianski, I. Frenkel, and A. Karagrigoriou, Eds. Cham: Springer International Publishing, 2018, pp. 213-225.

[16] Y. Lin, Y. Li, and E. Zio, "A Reliability Assessment Framework for Systems With Degradation Dependency by Combining Binary Decision Diagrams and Monte Carlo Simulation," IEEE Trans. Syst. Man, Cybern. Syst., vol. 46, no. 11, pp. 1556-1564, 2016.

[17] W. Wang, F. Di Maio, and E. Zio, "Three-loop Monte Carlo simulation approach to Multi-State Physics Modeling for system reliability assessment," Reliab. Eng. Syst. Saf., vol. 167, pp. 276-289, 2017.

[18] X. Zhao, C. Wu, S. Wang, and X. Wang, "Reliability analysis of multi-state k-out-of-n: G system with common bus performance sharing," Comput. Ind. Eng., vol. 124, pp. 359-369, 2018.

[19] B. Jafary and L. Fiondella, "A universal generating function-based multi-state system performance model subject to correlated failures," Reliab. Eng. Syst. Saf., vol. 152, pp. 16-27, 2016.

[20] Y. Liu, Q. Liu, C. Xie, and F. Wei, "Reliability assessment for multistate systems with state transition dependency," Reliab. Eng. Syst. Saf., vol. 188, pp. 276-288, 2019.

[21] A. Lisnianski and Y. Ding, "Using inverse Lz-transform for obtaining compact stochastic model of complex power station for short-term risk evaluation," Reliab. Eng. Syst. Saf., vol. 145, pp. 19-27, 2016.
[22] X. Song, Z. Zhai, Y. Liu, and J. Han, "A stochastic approach for the reliability evaluation of multi-state systems with dependent components," Reliab. Eng. Syst. Saf., vol. 170, pp. 257-266, 2018.

[23] X. Yang, Z. Lin, J. Ding, and Z. Long, "Lifetime Prediction of IGBT Modules in Suspension Choppers of Medium/Low-Speed Maglev Train Using an Energy-Based Approach," IEEE Trans. Power Electron., vol. 34, no. 1, pp. 738-747, 2019.

[24] C. D. Dao and M. J. Zuo, "Selective Maintenance for Multistate Series Systems With S-Dependent Components," IEEE Trans. Reliab., vol. 65, no. 2, pp. 525-539, 2016.

[25] V. Samavatian, Y. Avenas, and H. Iman-Eini, "Mutual and self-aging effects of power semiconductors on the thermal behaviour of DC-DC boost power converter," Microelectron. Reliab., vol. 88-90, no. May, pp. 493-499, 2018.

[26] S. Yang, A. Bryant, P. Mawby, D. Xiang, L. Ran, and P. Tavner, "An industry-based survey of reliability in power electronic converters," IEEE Trans. Ind. Appl., vol. 47, no. 3, pp. 1441-1451, 2011.

[27] H. Wang and F. Blaabjerg, "Reliability of capacitors for DC-link applications in power electronic converters - An overview," IEEE Trans. Ind. Appl., vol. 50, no. 5, pp. 3569-3578, 2014.

[28] S. H. Ali, S. Dusmez, and B. Akin, "Investigation of collector emitter voltage characteristics in thermally stressed discrete IGBT devices," ECCE 2016 - IEEE Energy Convers. Congr. Expo. Proc., 2016.

[29] S. H. Ali, M. Heydarzadeh, S. Dusmez, X. Li, A. S. Kamath, and B. Akin, "Lifetime Estimation of Discrete IGBT Devices Based on Gaussian Process," IEEE Trans. Ind. Appl., vol. 54, no. 1, pp. 395403, 2018.

[30] V. Samavatian, H. Iman-Eini, and Y. Avenas, "An efficient online time-temperature-dependent creep-fatigue rainflow counting algorithm," Int. J. Fatigue, vol. 116, pp. 284-292, 2018.

[31] M. Brincker, S. Söhl, R. Eisele, and V. N. Popok, "Strength and reliability of low temperature transient liquid phase bonded $\mathrm{CuSnCu}$ interconnects," Microelectron. Reliab., vol. 76-77, pp. 378-382, 2017.

[32] R. Chen et al., "Improvement of low-temperature impact toughness for 304 weld joint produced by laser-MIG hybrid welding under magnetic field," J. Mater. Process. Technol., vol. 247, pp. 306-314, Sep. 2017.

[33] W. Lai, M. Chen, L. Ran, O. Alatise, S. Xu, and P. Mawby, "Low $\Delta \mathrm{T}_{\mathrm{j}}$ Stress Cycle Effect in IGBT Power Module Die-Attach Lifetime Modeling," IEEE Trans. Power Electron., vol. 31, no. 9, pp. 65756585, 2016.

[34] I. F. Kovacevic, U. Drofenik, and J. W. Kolar, "New physical model for lifetime estimation of power modules," in The 2010 International Power Electronics Conference - ECCE ASIA -, 2010, pp. 2106-2114.

[35] R. Bayerer, T. Herrmann, T. Licht, J. Lutz, and M. Feller, "Model for power cycling lifetime of IGBT modules - various factors influencing lifetime," 5th Int. Conf. Integr. Power Syst., pp. 1-6, 2008.

[36] S. Yang, D. Xiang, A. Bryant, P. Mawby, L. Ran, and P. Tavner, "Condition Monitoring for Device Reliability in Power Electronic Converters: A Review," IEEE Trans. Power Electron., vol. 25, no. 11, pp. 2734-2752, 2010.

[37] H. Berg and E. Wolfgang, "Advanced IGBT modules for railway traction applications: Reliability testing," Microelectron. Reliab., vol. 38, no. 6-8, pp. 1319-1323, 1998.

[38] U. Scheuermann and S. Schuler, "Power cycling results for different control strategies," Microelectron. Reliab., vol. 50, no. 9-11, pp. 1203-1209, 2010.

[39] C. Durand, M. Klingler, D. Coutellier, and H. Naceur, "Power Cycling Reliability of Power Module: A Survey," IEEE Trans. Device Mater. Reliab., vol. 16, no. 1, pp. 80-97, 2016.

[40] D. Zhou, H. Wang, and F. Blaabjerg, "Mission Profile Based SystemLevel Reliability Analysis of DC/DC Converters for a Backup Power Application," IEEE Trans. Power Electron., vol. 33, no. 9, pp. 80308039, 2018. 